Check for updates

Cite this: Mater. Adv., 2022, 3,2779

Received 4th December 2021 Accepted 4th February 2022

DOI: $10.1039 / \mathrm{d} 1 \mathrm{ma} 01145 f$

rsc.li/materials-advances

\section{Study of the morphological, optical, structural and electrical properties of silicon nanowires at varying concentrations of the catalyst precursor $\dagger$}

\author{
Sadhna Rai, ${ }^{a}$ Rabina Bhujel, ${ }^{a}$ Manas Kumar Mondal, ${ }^{b}$ Bibhu Prasad Swain (D) *c and \\ Joydeep Biswas (DD *d
}

\begin{abstract}
Silicon nanowires (SiNWs) were grown by metal-assisted chemical etching of a p-type (100) silicon wafer. $\mathrm{AgNO}_{3}$ was used as a precursor for the metal catalyst (Ag). The concentration of $\mathrm{AgNO}_{3}$ was varied for studying the properties of SiNWs. SiNWs with the longest length $(11.49 \mu \mathrm{m})$ and smallest diameter $\left(55.05 \mathrm{~nm}\right.$ ) were obtained by using $20 \mathrm{mmol}$ of $\mathrm{AgNO}_{3}$ (20S). Their optical properties were studied using UV-Vis spectroscopy. The SiNWs showed space charge limited conduction characteristics. An ideality factor and a barrier height of 2.92 and $0.93 \mathrm{eV}$, respectively, were obtained for the $20 \mathrm{~S}$ sample.
\end{abstract}

\section{Introduction}

Nanostructures have benefits over their bulk counterparts in several aspects such as phonon, photon and electron confinement. One dimensional (1-D) nanostructures viz., nanorods, ${ }^{1,2}$ nanowires ${ }^{3-5}$ and helical structures ${ }^{6}$ show interesting morphologies, structures and properties. Thus, they are used for application in sensors, ${ }^{7-9}$ and biomedical, ${ }^{10,11}$ energy storage ${ }^{12-14}$ and optoelectronic devices. ${ }^{15-17}$ One such trending material explored in recent years is silicon nanowires (SiNWs). They show improved properties compared to bulk Si because of the quantum confinement effect. Due to their improved optical and electronic properties, they are widely studied for their application in nano-optoelectronic devices. ${ }^{18,19}$

The properties of SiNWs can be tailored by controlling their length, diameter and density. The bandgap in SiNWs can be tuned by varying various parameters. Kurokawa et al. reduced the diameter of SiNWs for tuning the bandgap. ${ }^{20}$ A bandgap value of $1.2 \mathrm{eV}$ for SiNWs of diameter $30 \mathrm{~nm}$ was obtained. Wendisch et al. used MACE and $\mathrm{KOH}$ etching to control the

\footnotetext{
${ }^{a}$ Centre for Materials Science and Nanotechnology,

Sikkim Manipal Institute of Technology, Sikkim Manipal University, Majhitar, 737136, East Sikkim, India

${ }^{b}$ Department of Metallurgical and Materials Engineering,

National Institute of Technology Durgapur, Durgapur 713209, India

${ }^{c}$ Department of Physics, National Institute of Technology, Manipur, Langol 795004,

Manipur, India.E-mail: bibhuprasad.swain@gmail.com,

bpswain@nitmanipur.ac.in

${ }^{d}$ Department of Chemistry, Sikkim Manipal Institute of Technology,

Sikkim Manipal University, Majhitar, 737136, East Sikkim, India.

E-mail: joyiisc@gmail.com, joydeep.biswas@smit.smu.edu.in

$\dagger$ Electronic supplementary information (ESI) available. See DOI: 10.1039/ d1ma01145f
}

microstructure of the SiNWs. ${ }^{21}$ Bisegmented nanowire arrays were generated using such a technique. These nanowires showed enhanced optical properties with controllable light absorption. Rahmani et al. varied the etching duration of $\mathrm{Si}$ to study the optical and electrical properties of the SiNWs. ${ }^{4}$ For an etching time of $30 \mathrm{~s}$, the SiNWs showed a broad band in photoluminescence spectra. It showed a rectifying behaviour with an ideality factor of 2.8 .

Various methods are used to fabricate SiNWs, such as vapour-solid-liquid (VLS) growth, ${ }^{18}$ chemical vapour deposition $(\mathrm{CVD}),{ }^{22}$ molecular beam epitaxy (MBE), ${ }^{23}$ and laser ablation..$^{24}$ However, these processes require sophisticated equipment. For the growth of SiNWs using these processes, high temperature and pressure have to be maintained. The overall cost of the production of SiNWs thus increases. In addition, the growth of nanowires is limited to a small area. These limitations can be overcome using a simple and cost-effective method, i.e., electroless metal-assisted chemical etching (EMACE). ${ }^{25}$

Over the years, researchers have made several modifications in EMACE to fabricate SiNWs. There are several factors on which the fabrication of SiNWs depends. Firstly, it depends on the type of metal catalyst used, its shape and the direction of movement. ${ }^{26,27}$ Secondly, it depends on the concentration of the etching solution $\left(\mathrm{H}_{2} \mathrm{O}_{2}\right.$ and $\left.\mathrm{HF}\right){ }^{28,29}$ Thirdly, the temperature also influences the growth of the nanowires. ${ }^{30}$ Lastly, the orientation of $\mathrm{Si}$ controls the direction of growth of the nanowires. ${ }^{31}$

Another critical factor that affects the fabrication of SiNWs is the metal catalyst concentration. Several groups of researchers have synthesised SiNWs by varying the concentration of AgNO3 viz., Cao et al., ${ }^{32}$ Venkatesan et al., ${ }^{32}$ Ozdemis et al., ${ }^{33}$ 
and Velez et al. ${ }^{34}$ However, their investigation was limited to the geometry and reflectance characteristics of the SiNWs. The other properties, such as the structural and electrical properties, were unexplored. In the present study, the SiNWs are synthesised by varying the concentration of $\mathrm{AgNO}_{3}$. We present a detailed study of the structural and electrical properties in addition to the morphological and optical properties of the SiNWs.

\section{Experimental details}

\section{Cleaning of silicon wafers}

The p-type Si wafers (p-Si) (orientation: $\langle 100\rangle$, thickness: $525 \pm 25 \mu \mathrm{m}$, resistivity: 1-10 $\Omega \mathrm{cm}$ ) were cleaned following the RCA cleaning procedure. The schematic for the cleaning process is given in Fig. S1 (ESI $\dagger$ ).

\section{Synthesis of SiNWs}

The RCA cleaned p-Si wafer was then electroplated by dipping in a solution containing $20 \mathrm{mmol} \mathrm{AgNO}_{3}$ and $4.8 \mathrm{M} \mathrm{HF}$. During this time, the Ag nanoparticles formed on the surface of Si. The wafer was removed and placed directly into an etching solution of $0.8 \mathrm{M} \mathrm{H}_{2} \mathrm{O}_{2}$ and $4.8 \mathrm{M} \mathrm{HF}$. It was left in this solution for $15 \mathrm{~min}$ to form SiNWs. Lastly, it was removed and placed in concentrated $\mathrm{HNO}_{3}$ for 30 min to remove the $\mathrm{Ag}$ nanoparticles. The same procedure was followed to optimise the etching time, viz., 30, 45 and $60 \mathrm{~min}$.

The optimum etching time was found to be $45 \mathrm{~min}$ after the SEM analysis. Now, in the electroplating step, the concentration of $\mathrm{AgNO}_{3}$ was varied as 10, 20 and $30 \mathrm{mmol}$. The rest of the procedure was the same as above. The samples were named 10S, $20 \mathrm{~S}$ and $30 \mathrm{~S}$, respectively.

\section{Characterisation studies}

The FESEM images and EDX spectra were obtained using a Carl Zeiss SIGMA equipped with an Element, AMETEK detector. AFM measurements were recorded on an INTEGRA (NT-MDTINTEGRA). Raman spectra were obtained using a Horiba Jobin Yvon (HR800-UV confocal) micro-Raman spectrometer using an excitation wavelength of $532 \mathrm{~nm}$. UV-Vis spectra were recorded on an Agilent Technologies, Czcerny 100 UV-Vis spectrophotometer. The sample size was $2.5 \mathrm{~cm} \times 2.5 \mathrm{~cm}$ and the scanning rate was $600 \mathrm{~nm} \mathrm{~min}^{-1}$. The current-voltage $(I-V)$ measurements were done using a KEYSIGHTB2901A source meter attached to the solar simulator (Class AAA), Model SS F5-3A with integrated Iris model: SS-O-Iris.

\section{Results and discussion}

\section{Mechanism}

The etching of the p-Si wafer was carried out in two steps, as shown in Fig. 1. In the first step, the RCA cleaned p-Si wafer was subjected to electroplating by $\mathrm{Ag}$ nanoparticles. $\mathrm{The}^{\mathrm{Ag}^{+}}$ions are reduced on the surface of $\mathrm{Si}$. Since $\mathrm{Ag}$ is more electronegative than $\mathrm{Si}$, it extracts electrons for the valence band of $\mathrm{Si}$.

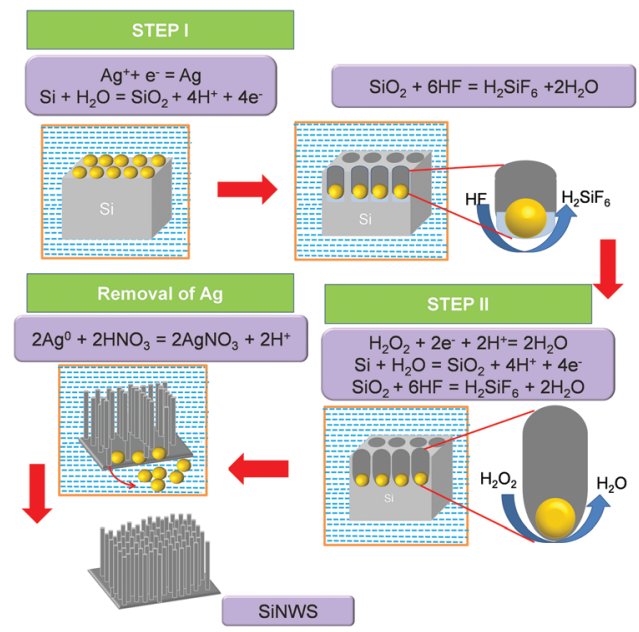

Fig. 1 Schematic illustration and mechanism for the synthesis of SiNWs using two step MACE.

Thus, it reduces $\mathrm{Ag}^{+}$to give $\mathrm{Ag}$ particles and accumulates holes below it. The Ag particles then act as a catalyst in the etching of Si. Si is oxidised to $\mathrm{SiO}_{2}$, further etched away by $\mathrm{HF}$ as $\mathrm{H}_{2} \mathrm{SiF}_{6}$.

In the second step, the electroplated $\mathrm{Si}$ is immersed in an aqueous solution of $\mathrm{HF}$ and $\mathrm{H}_{2} \mathrm{O}_{2}$. The interface between the AgNPs and SiNWs acts as the half cell where the galvanic exchange takes place between the $\mathrm{Ag}$ nanoparticles and $\mathrm{Si}$ wafer, as shown in Fig. 1. In the process, $\mathrm{Ag}^{+}$receives an electron from $\mathrm{Si}$ to form $\mathrm{Ag}$. $\mathrm{As}^{\mathrm{Ag}^{+}}$is reduced, the $\mathrm{Si}$ below the $\mathrm{Ag}$ particles is oxidised to $\mathrm{SiO}_{2}$. The $\mathrm{SiO}_{2}$ is then etched away by $\mathrm{HF}$ as soluble $\mathrm{H}_{2} \mathrm{SiF}_{6}$. The $\mathrm{Ag}$ particles are again oxidised by $\mathrm{H}_{2} \mathrm{O}_{2}$ to $\mathrm{Ag}^{+}$ions. The cycle is repeated until the wafer is removed from the etching solution, as shown in Fig. 1. Lastly, the $\mathrm{Ag}$ particles are removed by $\mathrm{HNO}_{3}$. The $\mathrm{Ag}$ particles react with $\mathrm{HNO}_{3}$ to form $\mathrm{AgNO}_{3}$ again, washed away by water.

\section{Optimisation of etching time}

First, the clean $\mathrm{p}$-Si wafer was electroplated in a solution containing a $20 \mathrm{mmol} \mathrm{AgNO}_{3}$ and a $4.8 \mathrm{M} \mathrm{HF}$ solution for $60 \mathrm{~s}$. The silicon wafer was then etched at various etching times viz., 15, 30, 45 and $60 \mathrm{~min}$. The FESEM images of the respective SiNWs are shown in Fig. 2. The length of the nanowires was measured using Image J software. A plot of nanowire length versus the etching time is given in Fig. 3. The length of the

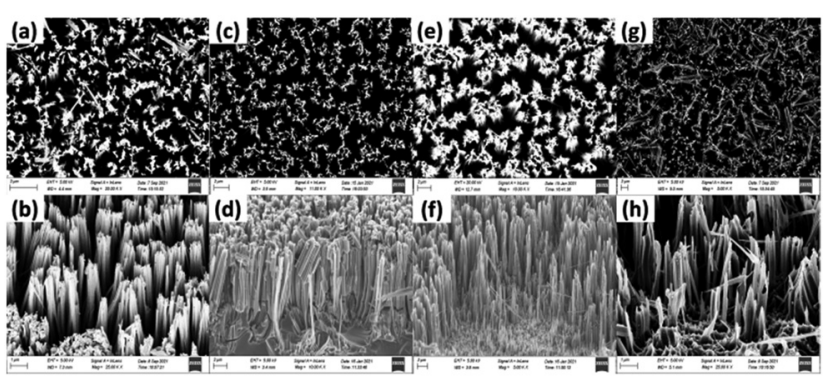

Fig. 2 Top and cross-sectional view FESEM images of SiNWs etched at ( $a$ and b) $15 \mathrm{~min}$, (c and d) $30 \mathrm{~min}$, (e and f) $45 \mathrm{~min}$ and ( $\mathrm{g}$ and h) $60 \mathrm{~min}$. 


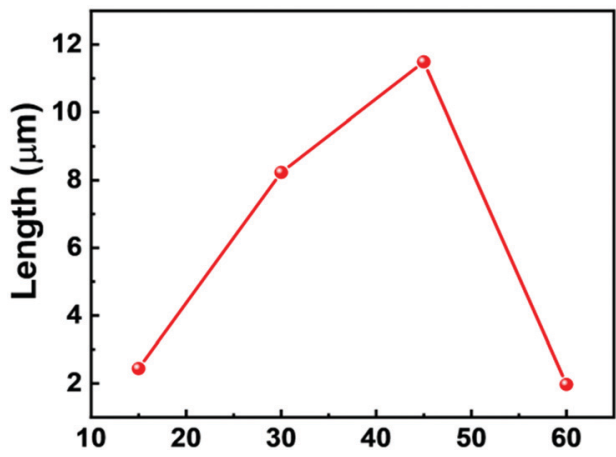

Fig. 3 Etching time versus time plot for SiNWs.

nanowires increased with an increase in the etching time. A similar trend was observed in previous studies by other researchers viz., Doudi et al. ${ }^{35}$ and Gaidi et al. ${ }^{36}$ With the increase in etching time, the topology of the nanowires also changed. As the length of the nanowires increase, they become more flexible and bending takes place. As a result, the tips are flocked together due to van der Waals attractive force. ${ }^{36}$

However, the length of the nanowires decreased drastically at $60 \mathrm{~min}$. This may be because the silicon wafer was exposed to etching solution for too long, which led to excessive etching of the Si wafer. This excessive etching resulted in snapping of the nanowires as seen in Fig. $2 \mathrm{~g}$ and $\mathrm{h}$. The longest length was achieved at $45 \mathrm{~min}$.

\section{Variation of the concentration of $\mathrm{AgNO}_{3}$}

Furthermore, taking $45 \mathrm{~min}$ as the optimum time, the concentration of $\mathrm{AgNO}_{3}$ was varied. In Fig. 3, the low and high magnification FESEM images of Ag nanoparticles deposited on p-Si are shown. From the mechanism, we saw that the nucleation of $\mathrm{Ag}$ nanoparticles on the $\mathrm{Si}$ wafer takes place as $\mathrm{p}-\mathrm{Si}$ is dipped in the aqueous solution of $\mathrm{AgNO}_{3} / \mathrm{HF}$. Here, the authors have varied the concentration of $\mathrm{AgNO}_{3}$, viz., 10, 20 and $30 \mathrm{mmol}$, named 10A, 20A and 30A, respectively.

The FESEM image of 10A (Fig. 4a) shows that the Ag nanoparticles are densely formed on the surface of p-Si. In the magnified image (Fig. 4b), it is seen that the nanoparticles possess a spaghetti-like structure. As the concentration of the $\mathrm{AgNO}_{3}$ is increased to $20 \mathrm{mmol}$, the $\mathrm{Ag}$ nanoparticles start to agglomerate together (Fig. 4c) in 20A. With the increase in the concentration of salt, the nucleation is more and the $\mathrm{Ag}$ nanoparticles are agglomerated together, leading to the formation of dendrites in addition to spherical nanoparticles (Fig. 4d). At the maximum concentration of 30A, rod-like structures are also visible in addition to spherical nanoparticles (Fig. 4e). Since no factor is known to control the growth of the $\mathrm{Ag}$ nucleus, the agglomeration takes place in random directions and hence different morphologies are observed.

The EDX analysis and elemental mapping of 10A, 20A and 30A are presented in Fig. S2 (ESI $\dagger$ ). The percentage composition of $\mathrm{Ag}$ increased as the concentration of $\mathrm{AgNO}_{3}$ was increased. The lowest and highest percentage of $\mathrm{Ag}$ is observed for $10 \mathrm{~A}$ and $30 \mathrm{~A}$, respectively. In the case of $20 \mathrm{~A}$, some percentage of

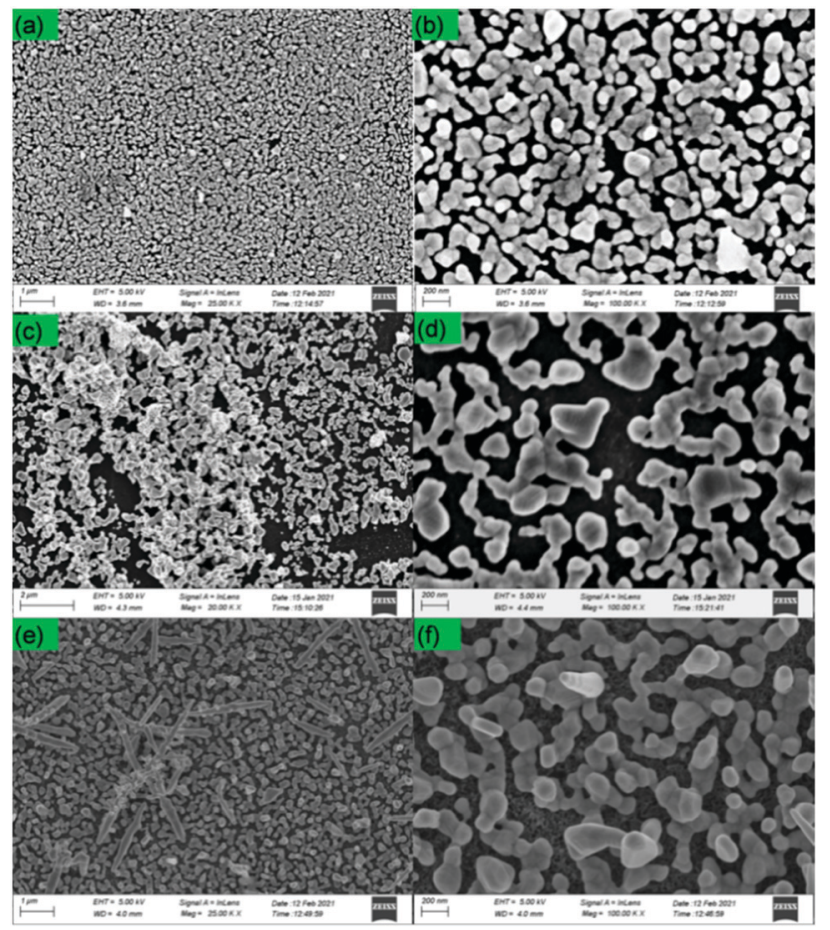

Fig. 4 FE-SEM images at different magnifications for 10A ( $a$ and $b$ ), $20 \mathrm{~A}$ (c and d) and 30A (e and f).

oxygen is also present. It may be due to the formation of $\mathrm{Ag}_{2} \mathrm{O}$ by the reaction of Ag with the atmospheric oxygen.

Again, the morphology of the Ag NPs formed on the p-Si was studied using AFM. In Fig. S3a (ESI $\dagger$ ), Ag nanoparticles show minimum agglomeration and the particles are quite distant from one another. However, the Ag NPs are agglomerated more in the case of 20A. The NPs are less distant from one another and densely formed on p-Si (Fig. S3b, ESI $\dagger$ ). In some places, the NPs are separate and in other places, they come together to form lumps. The Ag NPs are most dense in the case of 30A (Fig. S3c, ESI $\dagger$ ). The Ag NPs are clumped together; and as a result, they form a rod-like structure. The results were the same as those observed from FESEM analysis. The average roughness values for $10 \mathrm{~A}, 20 \mathrm{~A}$ and $30 \mathrm{~A}$ are $0.275,2.097$ and $2.318 \mu \mathrm{m}$, respectively. The roughness values increased as the concentration of $\mathrm{AgNO}_{3}$ was increased.

From the top view of the FESEM images of the SiNWs, it is observed that for the nanowires in $10 \mathrm{~S}$ the tips of the nanowires are not separated properly. In this case, nanoparticles have hole formation, as shown in Fig. $5 \mathrm{a}$ and b. Since the atomic\% of $\mathrm{Ag}$ was low, this amount was not enough to form well-separated nanowires. As the concentration is increased to $20 \mathrm{mmol}$, though some agglomeration is present, most of the nanowires are well-formed and the tips are separated (Fig. $5 \mathrm{~d}$ and e). In this case, free-standing and vertical nanowires are formed as seen in the cross-sectional view of the FESEM image (Fig. 5f). However, when the concentration increases to $30 \mathrm{mmol}$, the nanowires are deformed. At $30 \mathrm{mmol}$ large rod-shaped and agglomerated Ag particles were formed, as seen in Fig. 4e. 


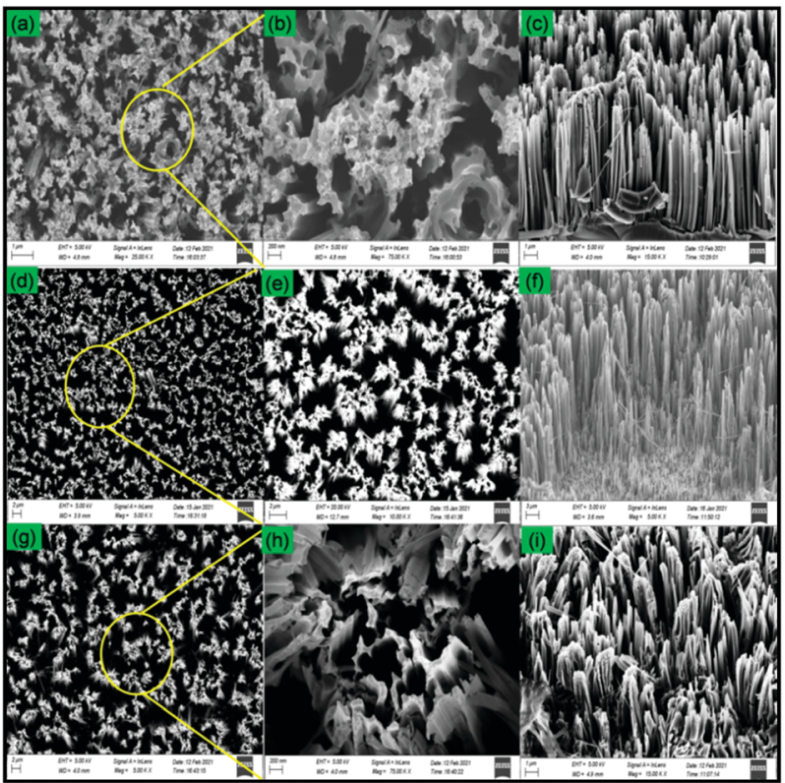

Fig. 5 Top view FESEM images of (a) 10S, (d) 20S, (g) $30 \mathrm{~S}$ and their magnified images (b, e and h). Cross-sectional FESEM images of (c) 10S, (f) $20 \mathrm{~S}$ and (g) $30 \mathrm{~S}$.

These particles may have led to the formation of large holes. Also, the high content of the Ag catalyst led to the excessive oxidation of $\mathrm{Si}$, leading to uncontrolled etching of the Si. Hence, at $30 \mathrm{mmol}$ well-defined SiNWs were not formed (Fig. 5i).

From the cross-sectional view of the SEM images of $10 \mathrm{~S}, 20 \mathrm{~S}$ and $30 \mathrm{~S}$, the lengths of the nanowires were measured. For this purpose, Image J software was used. The average values of the length of the SiNWs are provided in Table 1 . The length of nanowires increases in the order $30 \mathrm{~S}<10 \mathrm{~S}<20 \mathrm{~S}$. The longest length is that for 20S, i.e., $11.49 \mu \mathrm{m}$. From the FESEM analysis, it is found that well defined vertical SiNWs with the longest lengths are synthesised at $20 \mathrm{mmol}$ of $\mathrm{AgNO}_{3}$.

The elemental mapping and the EDX spectra for 10S, $20 \mathrm{~S}$ and $30 \mathrm{~S}$ are presented in Fig. S4 (ESI $\dagger$ ). The elements present and their weight\% and atomic\% are shown in the EDX spectra. The main elements present are $\mathrm{Si}$ and $\mathrm{O}$. A small amount of $\mathrm{Ag}$ is present in the $20 \mathrm{~S}$ due to the formation of $\mathrm{Ag}_{2} \mathrm{O}$ formed in the electroplating process. This was not removed even after washing in $\mathrm{HNO}_{3}$.

From the AFM images of SiNWs (Fig. 6a-d), it is clear that $10 \mathrm{~S}$ and $30 \mathrm{~S}$ show agglomeration, whereas $20 \mathrm{~S}$ shows well-defined

Table 1 Data obtained from AFM and FESEM analysis for 10S, $20 \mathrm{~S}$ and $30 \mathrm{~S}$

\begin{tabular}{lclll}
\hline Sample code & Length $(\mu \mathrm{m})$ & Diameter $(\mathrm{nm})$ & $R_{\mathrm{a}}(\mu \mathrm{m})$ & $R_{\mathrm{s}}(\mu \mathrm{m})$ \\
\hline 10S & 5.86 & 63.94 & 3.72 & 0.674 \\
20S & 11.49 & 55.05 & 0.97 & 0.263 \\
30S & 3.11 & 88.16 & 3.94 & 1.21
\end{tabular}

The $R_{\mathrm{a}}$ and $R_{\mathrm{q}}$ values are maximum for $30 \mathrm{~S}$, which shows minimum uniformity. In contrast, these values are minimum for the $20 \mathrm{~S}$ sample, indicating maximum uniformity. This was also seen from the SEM and AFM images. Similar results were observed by Chhetri et al. ${ }^{37}$

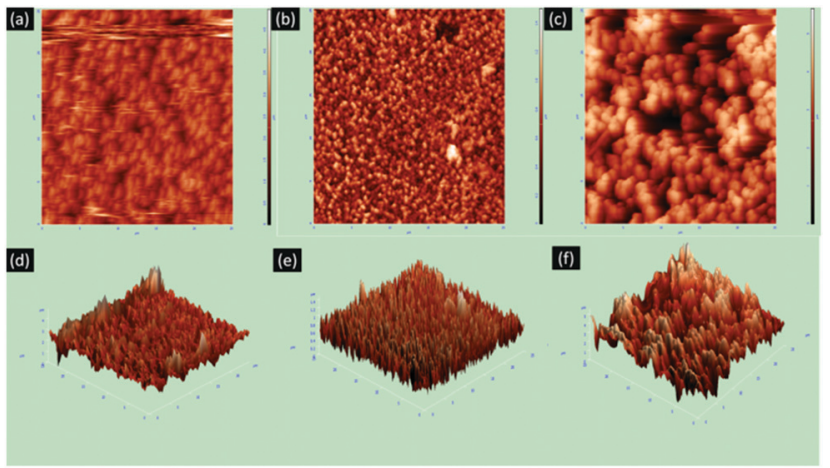

Fig. 6 2D and 3D AFM images of ( $a$ and d) 10S, (b and e) 20S and (c and f) 30 respectively.

nanowires. The diameter of the nanowires was calculated using the Gwyddion software. To measure the diameter, a line was drawn diagonally across the 3D AFM images of the SiNWs using a feature in the application called the line profile. Several peaks were then obtained. By taking the average of the width of the peaks, the diameter of the nanowires was obtained. The line profile of the peaks obtained after drawing the diagonals is shown in Fig. S6 (ESI $\dagger)$. The average diameters of the nanowires are provided in Table 1 . The $20 \mathrm{~S}$ showed the smallest value for the diameter, i.e., $55.05 \mathrm{~nm}$. As seen from the SEM and AFM images, $10 \mathrm{~S}$ and $30 \mathrm{~S}$ showed higher diameter values because the NWs were agglomerated together. The values for average roughness $\left(R_{\mathrm{a}}\right)$ and root mean square roughness $\left(R_{\mathrm{q}}\right)$ were obtained from Gwyddion. The values are incorporated in Table 1.

\section{Optical properties}

The optical properties of silicon nanowires were studied using diffuse surface reflectance analysis. The reflectance for SiNWs was measured in the range of 200 to $800 \mathrm{~nm}$ (Fig. 7). The reflectance for SiNWs is observed to decrease in the range of 300 to $400 \mathrm{~nm}$ (UV region). In this range, the reflectance for $30 \mathrm{~S}$ was minimum $(4.06 \%)$. However, the reflectance increases gradually in the range of 400 to $800 \mathrm{~nm}$ (visible region). Finally, at $800 \mathrm{~nm}$, the reflectance for the $20 \mathrm{~S}$ sample $(15.39 \%)$ is lower than those for $10 \mathrm{~S}$ and $30 \mathrm{~S}$. The nanowires show different values of reflectance at different wavelengths. Hence, the values of maximum reflectance $\left(R_{\max }\right)$ and minimum reflectance $\left(R_{\min }\right)$ in the UV and visible range are extracted and compiled in Table 2. The difference in the reflectance values for SiNWs

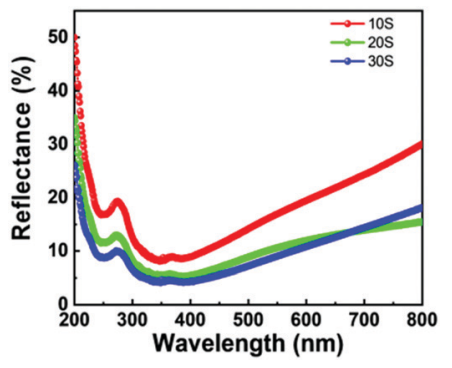

Fig. 7 Reflectance spectra of 10S, 20S, and 30S. 
Table 2 Data obtained from reflectance spectra for 10S, 20S and 30S

\begin{tabular}{llllll}
\hline & \multicolumn{2}{l}{ UV region } & & & \multicolumn{2}{c}{ Visible region } \\
\cline { 2 - 3 } Sample code & $R_{\max }(\%)$ & $R_{\min }(\%)$ & & $R_{\max }(\%)$ & $R_{\min }(\%)$ \\
\hline $10 \mathrm{~S}$ & 8.13 & 19.17 & & 8.73 & 30.00 \\
$20 \mathrm{~S}$ & 5.26 & 13.12 & & 5.35 & 15.39 \\
$30 \mathrm{~S}$ & 4.06 & 9.82 & & 4.35 & 18.06
\end{tabular}

may be due to various reasons such as length, ${ }^{38}$ diameter, ${ }^{39}$ shape, density ${ }^{40}$ and porosity ${ }^{41}$ of the nanowires.

\section{Structural properties}

Fig. 8 presents the Raman spectra of $\mathrm{Si}$ and the SiNWs synthesised using different concentrations of $\mathrm{AgNO}_{3}$. These spectra were obtained using an excitation wavelength of $532 \mathrm{~nm}$ and a power of $50 \mathrm{~mW}$. The signature peak for planar $\mathrm{Si}$ is centered at $520.7 \mathrm{~cm}^{-1}$. ${ }^{42}$ However, for the SiNWs, a redshift is observed for all the samples with a broadening of the peak. The peaks of $10 \mathrm{~S}, 20 \mathrm{~S}$ and $30 \mathrm{~S}$ are centered at 515.8, 518.3 and $519.3 \mathrm{~cm}^{-1}$, respectively. The redshift may be due to the phonon confinement. ${ }^{25}$ The nanowires have a large surface area compared to the bulk Si. Hence, an increase in the intensity of the peaks for SiNWs has been observed in Fig. $8 .^{43}$ The SiNWs with longer lengths showed higher intensity. Similar results were observed by Rodichkina et al. ${ }^{44}$ The increased intensity may be due to the enhanced transmission excitation. ${ }^{25}$ The higher intensities of the Raman spectra suggest that the SiNWs are highly crystalline.

The full width at half maximum (FWHM) value for p-Si was $7.84 \mathrm{~cm}^{-1}$. However, the peaks for the SiNWs were broadened, showing FWHM values of 18.11, 10.35 and $16.92 \mathrm{~nm}$ for $10 \mathrm{~S}$, $20 \mathrm{~S}$ and 30S, respectively. The peak broadenings for the nanowires with larger diameters are more than those with smaller diameters. $20 \mathrm{~S}$ has the smallest diameter $(55.05 \mathrm{~nm})$ as calculated from AFM and has the lowest value of FWHM.

\section{Electrical properties}

The front contact was made on $\mathrm{Si}$ and SiNWs using Ag paste to measure the electrical properties. The dark and photocurrent

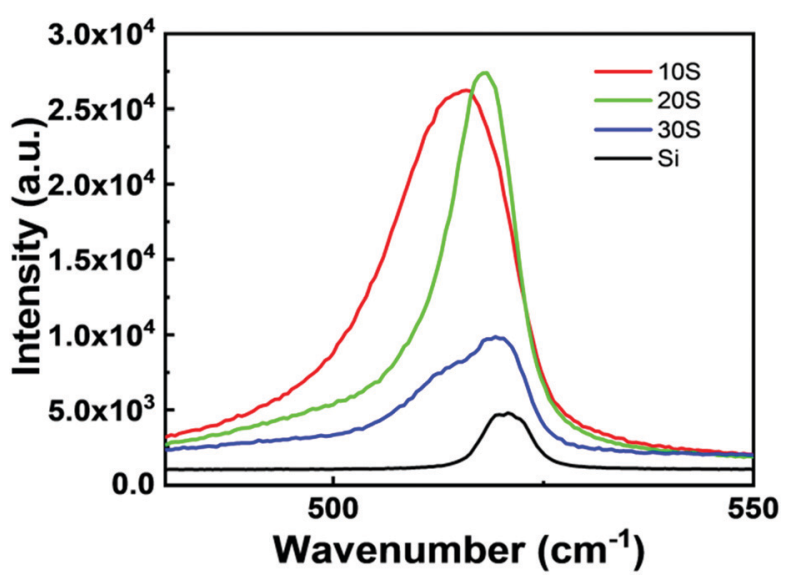

Fig. 8 Raman spectra of Si, 10S, 20S and 30S. measurement was done in a solar simulator. The $I-V$ measurements were done by applying a bias from -3 to $3 \mathrm{~V}$. The photocurrent was obtained by illuminating the samples under 1 Sun irradiation. The dark and photocurrent responses of $\mathrm{Ag} / \mathrm{Si}$ and $\mathrm{Ag} / \mathrm{SiNW} / \mathrm{Si}$ are shown in Fig. 9. It is observed that the current is the lowest for $\mathrm{Ag} / \mathrm{Si}$ under both dark and light conditions. The reason is that the planar silicon has an indirect bandgap. When planar $\mathrm{Si}$ is converted to nanowires, the indirect bandgap changes to the direct bandgap facilitating the easy movement of electrons. Also, SiNWs have a lower reflectance value than planar Si. The more the light absorbed, the more its utilisation for electron excitation, increasing the current. Among the SiNWs, Ag/20S/Si shows the highest current under illumination. This is because it has the lowest reflectivity seen from UV-Vis spectroscopy. It has the smallest diameter and longest length. So, it has the highest ability to trap light. In addition, the mobility of the charge carrier in the case of SiNWs depends on the diameter of the nanowires. The smaller the diameter, the higher the mobility. ${ }^{45}$ This also explains the higher current response of the $\mathrm{Ag} / 20 \mathrm{~S} / \mathrm{Si}$.

All the samples show diode characteristics with rectification characteristics. The rectification ratio is calculated by dividing the current in forwarding bias by reverse bias at the same voltage. The rectification ratios of $\mathrm{Ag} / 10 \mathrm{~S} / \mathrm{Si}, \mathrm{Ag} / 20 \mathrm{Si}$ and $\mathrm{Ag} / 30 \mathrm{~S} / \mathrm{Si}$ samples are listed in Table 3 . The diode $\mathrm{Ag} / 20 \mathrm{~S}$ shows the highest rectification ratio of 83.50 at $2 \mathrm{~V}$.

The ideality factor $(\eta)$ and barrier height $\left(\varphi_{\mathrm{b}}\right)$ of a Schottky diode is calculated using the following equations ${ }^{46}$

$$
I=I_{\mathrm{S}}\left(\mathrm{e}^{\frac{q\left(V-R_{\mathrm{S}} I\right)}{\eta k T}}-1\right)
$$

here, $q, V, k, T$ and $I_{\mathrm{s}}$ refer to the electron charge, applied voltage, Boltzmann's constant, absolute temperature and reverse saturation current, respectively.

$$
I_{\mathrm{s}}=a A^{*} T^{2} \mathrm{e}^{\left(-\frac{q \varphi_{b}}{k T}\right)}
$$

Here, $a$ and $A^{*}$ refer to the effective area of the diode $\left(1 \mathrm{~cm}^{2}\right)$ and Richardson's constant $\left(32 \mathrm{~A} \mathrm{~cm}^{-2} \mathrm{~K}^{-2}\right.$ for $\mathrm{p}$-Si).

The ideality factor and barrier height values calculated from the $I-V$ plot is presented in Table 3. The ideality factor and barrier height of the $\mathrm{Ag} / \mathrm{Si}$ is 1.25 and $0.31 \mathrm{eV}$, respectively. It is evident that the $\eta$ values decrease with the increase in the concentration of $\mathrm{AgNO}_{3}$. The ideality factor observed in this
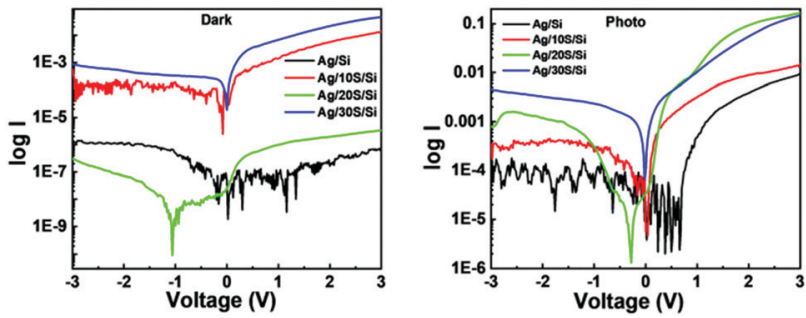

Fig. 9 Dark and photo current response of $\mathrm{Ag} / \mathrm{Si}, \mathrm{Ag} / 10 \mathrm{~S} / \mathrm{Si}, \mathrm{Ag} / 20 \mathrm{~S} / \mathrm{Si}$ and $\mathrm{Ag} / 3 \mathrm{OS} / \mathrm{Si}$. 
Table 3 Data obtained from $I-V$ analysis

\begin{tabular}{llll}
\hline Sample code & Rectification ratio & Ideality factor & Barrier height $(\mathrm{eV})$ \\
\hline $\mathrm{Ag} / \mathrm{Si}$ & & 1.25 & 0.31 \\
$\mathrm{Ag} / 10 \mathrm{~S} / \mathrm{Si}$ & 23.18 & 3.93 & 1.06 \\
$\mathrm{Ag} / 20 \mathrm{~S} / \mathrm{Si}$ & 83.50 & 2.92 & 0.93 \\
$\mathrm{Ag} / 30 \mathrm{~S} / \mathrm{Si}$ & 16.66 & 2.42 & 1.21
\end{tabular}

study is considerably lower than that obtained by Wang et al. (3.51 to 4.62$)^{47}$ and Rahmani et al. (2.8 to 5.4$) .{ }^{4}$ The deviation of the ideality factor from unity may be due to the presence of an oxide layer in SiNWs. ${ }^{48}$

The barrier height of the SiNWs decreased with the decrease in their diameter. The barrier height of the $20 \mathrm{~S}$ is observed to be the lowest since it has the smallest diameter. The result of the present study is consistent with the results in the literature. Several reasons have been proposed for the dependency of the diameter of nanowires on the barrier height viz. electron-hole recombination in the depletion region, ${ }^{49}$ the presence of interface states in the nanowires, ${ }^{50}$ the presence of positive charge around the nanowire and surface state density. ${ }^{51}$ The low value of $\mathrm{Ag} / \mathrm{Si}$ may be due to lower recombination losses than the diodes for SiNWs. In the present work, the density of the nanowires increased as the diameter increased, which was observed in the FESEM analysis. Hence, the lower barrier height may be due to a larger density of nanowires with a smaller diameter. The decrease in the barrier height may also be attributed to the presence of the oxide layer and defect states in SiNWs. A similar result was observed in a recent work by $\mathrm{Hu}$ et al. $^{48}$

$\log I$ versus $\log V$ was plotted to investigate the conduction mechanism in the SiNW samples, which is presented in Fig. 10. The behaviour of the junctions suggests that they follow the power-law $I \sim V^{m}$, where $m$ represents the slope of the curve. The $10 \mathrm{~S}$ and $30 \mathrm{~S}$ samples show two values of $\mathrm{m}$. In the low voltage region, they show ohmic behaviour. In contrast, they follow the space charge limited conduction (SCLC) mechanism at a higher voltage. The SiNWs have a high surface to volume ratio. The surface states lead to the depletion of charge carriers. As a result, the trapped SCLC affects the charge transport. ${ }^{4}$

Furthermore, in the case of 20S, four values of $m$ are observed. The 20S sample shows Ohmic behaviour in the low voltage region, shallow trap SCLC followed by trap-filled limited SCLC in the medium voltage region and trap free SCLC regime
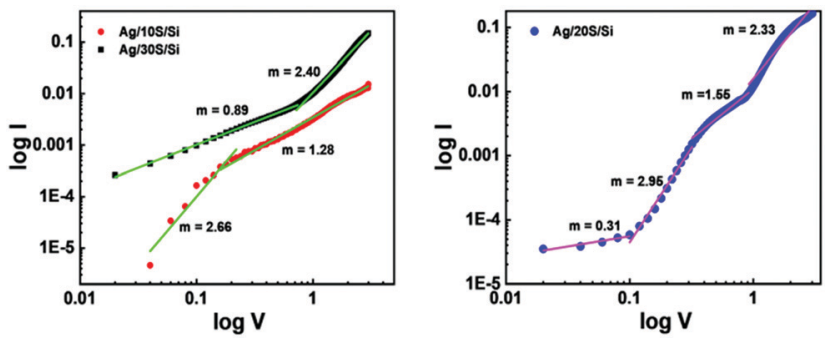

Fig. $10 \mathrm{Log} /$ vs. $\log V$ plot of Ag/10S/Si, Ag/30S/Si and Ag/20S/Si diode. $m$ is the slope of the curve. at higher voltage region. ${ }^{52}$ The SiNWs follow the SCLC mechanism due to defect or trap states. ${ }^{53}$ As the density increases, the number of traps increases. So the different behaviour of the $20 \mathrm{~S}$ sample may be because it has the highest density. Also, it has the highest oxygen content; as a result, there will be a large number of trapping states at the $\mathrm{Ag} / \mathrm{SiNW}$ interface. The results show that the SiNW junctions transit from ohmic behaviour in the low voltage region to the SCLC behaviour in the high voltage region. Similar results were reported by other research groups working with SiNWs. ${ }^{4,54}$

\section{Conclusions}

SiNWs were synthesised by following two step MACE. The concentration of $\mathrm{AgNO}_{3}$ was varied as 10, 20 and $30 \mathrm{mmol}$. The etching time was optimised as $45 \mathrm{~min}$. The length and diameter of the nanowires were calculated from FESEM and AFM analysis, respectively. The 20S sample showed the longest length $(11.49 \mu \mathrm{m})$ and smallest diameter $(55.05 \mathrm{~nm})$. The ideality factor and barrier were calculated from the $I-V$ plot. For the 20S sample, the ideality factor and barrier height were calculated as 2.92 and $0.93 \mathrm{eV}$.

\section{Author contributions}

Sadhna Rai: Conceptualisation, methodology, writing the original draft; Rabina Bhujel: Methodology and formal analysis; Manas Kumar Mondal: Formal analysis; Bibhu P. Swain: Supervision, review \& editing; Joydeep Biswas: Supervision, review \& editing.

\section{Conflicts of interest}

On behalf of all authors, the corresponding authors state that there are no conflicts to declare.

\section{Acknowledgements}

Ms Sadhna Rai acknowledges the UGC-DAE-CSR, Indore (Project Ref: CSR-IC-MSR-07/CRS-215/2017-18/1296), for a Grant-in-Aid for a Junior Research Fellowship. The authors acknowledge the Sophisticated Analytical Instrumentation Facility, IIT Bombay, for providing UV-Vis spectroscopy and Raman spectroscopy characterisation facilities. The authors also acknowledge the Centre of Excellence in Advanced Materials, NIT Durgapur, and Instrumentation Facility, IIT Roorkee, for their help in acquiring FESEM and AFM images, respectively.

\section{References}

1 Q. Chen, R. Zhu, S. Liu, D. Wu, H. Fu, J. Zhu and H. He, J. Mater. Chem. A, 2018, 6, 6356-6362.

2 L. Schlur, J. R. Calado and D. Spitzer, R. Soc. Open Sci., 2018, 5, 180510. 
3 R. Bhujel, S. Rai and B. P. Swain, Mater. Sci. Semicond. Process., 2019, 102, 104592.

4 M. Rahmani, S. Amdouni, M. Zaïbi and A. Meftah, Silicon, 2021, 13, 179-187.

5 N.-H. Tran, T.-H. Duong and H.-C. Kim, Sci. Rep., 2017, 7, 15093.

6 Z. Ren and P.-X. Gao, Nanoscale, 2014, 6, 9366.

7 T. F. Choo, N. U. Saidin and K. Y. Kok, R. Soc. Open Sci., 2018, 5, 172372.

8 L. Shahriary, S. K. Haram and A. A. Athawale, Talanta, 2013, 104, 212-218.

9 H. A. Wahab, A. A. Salama, A. A. El Saeid, M. Willander, O. Nur and I. K. Battisha, Results Phys., 2018, 9, 809-814.

10 Y. P. Ivanov, A. Alfadhel, M. Alnassar, J. E. Perez, M. Vazquez, A. Chuvilin and J. Kosel, Sci. Rep., 2016, 6, 24189.

11 J. Xu, Y. Xue, J. Cao, G. Wang, Y. Li, W. Wang and Z. Chen, RSC Adv., 2016, 6, 5541-5546.

12 V. H. Luan, J. H. Han, H. W. Kang and W. Lee, Composites, Part B, 2019, 178, 107464.

13 R. Kumar, A. Soam, R. O. Dusane and P. Bhargava, J. Mater. Sci.: Mater. Electron., 2018, 29, 1947-1954.

14 W. Pan, M. Zhang, F. Gui, Y. Han and X. Sun, Mater. Res. Bull., 2022, 145, 111549.

15 L.-B. Luo, X.-H. Wang, C. Xie, Z.-J. Li, R. Lu, X.-B. Yang and J. Lu, Nanoscale Res. Lett., 2014, 9, 637.

16 M. Ding, Z. Guo, L. Zhou, X. Fang, L. Zhang, L. Zeng, L. Xie and H. Zhao, Crystals, 2018, 8, 223.

17 Y. Li, F. Qian, J. Xiang and C. M. Lieber, Mater. Today, 2006, 9, 18-27.

18 M. Shao, D. D. D. Ma and S. Lee, Eur. J. Inorg. Chem., 2010, 4264-4278.

19 M. K. Sahoo and P. Kale, J. Materiomics, 2019, 5, 34-48.

20 Y. Kurokawa, M. Yano, S. Miyajima and A. Yamada, Jpn. J. Appl. Phys., 2017, 56, 04 CS03.

21 F. J. Wendisch, M. Abazari, H. Mahdavi, M. Rey, N. Vogel, M. Musso, O. Diwald and G. R. Bourret, ACS Appl. Mater. Interfaces, 2020, 12, 13140-13147.

22 O. Demichel, F. Oehler, V. Calvo, P. Noé, N. Pauc, P. Gentile, P. Ferret, T. Baron and N. Magnea, Phys. E, 2009, 41, 963-965.

23 P. Werner, N. D. Zakharov, G. Gerth, L. Schubert and U. Gösele, Int. J. Mater. Res., 2006, 97, 1008-1015.

24 V. Schmidt, J. V. Wittemann, S. Senz and U. Gösele, Adv. Mater., 2009, 21, 2681-2702.

25 R. Bhujel, U. Rizal, A. Agarwal, B. S. Swain and B. P. Swain, J. Mater. Eng. Perform., 2018, 27, 2655-2660.

26 K. A. Gonchar, V. Y. Kitaeva, G. A. Zharik, A. A. Eliseev and L. A. Osminkina, Front. Chem., 2019, 7, 1-7.

27 F. J. Wendisch, M. Rey, N. Vogel and G. R. Bourret, Chem. Mater., 2020, 32, 9425-9434.

28 Y. Liu, G. Ji, J. Wang, X. Liang, Z. Zuo and Y. Shi, Nanoscale Res. Lett., 2012, 7, 663.

29 A. Najar, A. B. Slimane, M. N. Hedhili, D. Anjum, R. Sougrat, T. K. Ng and B. S. Ooi, J. Appl. Phys., 2012, 112, 033502.
30 O. Fellahi, T. Hadjersi, M. Maamache, S. Bouanik and A. Manseri, Appl. Surf. Sci., 2010, 257, 591-595.

31 Z. Huang, N. Geyer, P. Werner, J. de Boor and U. Gösele, Adv. Mater., 2011, 23, 285-308.

32 D. T. Cao, L. T. Q. Ngan, T. Van Viet and C. T. Anh, Int. J. Nanotechnol., 2013, 10, 343.

33 B. Ozdemir, M. Kulakci, R. Turan and H. E. Unalan, Nanotechnology, 2011, 22, 155606.

34 V. Velez and K. Sundaram, Int. J. Nanosci. Nanotechnol., 2017, 13, 283-288.

35 K. Daoudi, K. Ramachandran, H. Alawadhi, R. Boukherroub, E. Dogheche, M. A. El Khakani and M. Gaidi, Surf. Interfaces, 2021, 27, 101454.

36 M. Gaidi, K. Daoudi, S. Columbus, A. Hajjaji, M. A. El Khakani and B. Bessais, J. Environ. Sci., 2021, 101, 123-134.

37 N. Chhetri, S. Haldar and S. Chatterjee, Mater. Res. Express, 2020, 6, $1250 \mathrm{i} 2$.

38 V. T. Pham, M. Dutta, H. T. Bui and N. Fukata, Adv. Nat. Sci.: Nanosci. Nanotechnol., 2014, 5, 045014.

39 S. A. Razek, M. A. Swillam and N. K. Allam, J. Appl. Phys., 2014, 115, 194305.

40 K.-Q. Peng and S.-T. Lee, Adv. Mater., 2011, 23, 198-215.

41 P. Parashar, D.-R. Jian, W. Huang, Y.-W. Huang and A. Lin, IEEE 44th Photovoltaic Specialist Conference (PVSC), 2017, 1631-1634.

42 S. A. Mala, L. Tsybeskov, D. J. Lockwood, X. Wu and J.-M. Baribeau, J. Appl. Phys., 2014, 116, 014305.

43 S. Weidemann, M. Kockert, D. Wallacher, M. Ramsteiner, A. Mogilatenko, K. Rademann and S. F. Fischer, J. Nanomater., 2015, 2015, 1-11.

44 S. P. Rodichkina, L. A. Osminkina, M. Isaiev, A. V. Pavlikov, A. V. Zoteev, V. A. Georgobiani, K. A. Gonchar, A. N. Vasiliev and V. Y. Timoshenko, Appl. Phys. B: Lasers Opt., 2015, 121, 337-344.

45 J. Ramanujam, D. Shiri and A. Verma, Mater. Express, 2011, 1, 105-126.

46 M. Rahmani and A. Meftah, J. Mater. Sci.: Mater. Electron., 2020, 31, 16352-16359.

47 Z. Wang, M. Zhu, X. Chen, Q. Yan and J. Zhang, Microelectron. Eng., 2013, 103, 36-41.

48 X. F. Hu, S. J. Li, J. Wang, Z. M. Jiang and X. J. Yang, Nanoscale Res. Lett., 2020, 15, 52.

49 F. Léonard, A. A. Talin, B. S. Swartzentruber and S. T. Picraux, Phys. Rev. Lett., 2009, 102, 106805.

50 K. Yoon, J. K. Hyun, J. G. Connell, I. Amit, Y. Rosenwaks and L. J. Lauhon, Nano Lett., 2013, 13, 6183-6188.

51 A. Soudi, C.-H. Hsu and Y. Gu, Nano Lett., 2012, 12, 5111-5116.

52 P. Zhang, Y. S. Ang, A. L. Garner, Á. Valfells, J. W. Luginsland and L. K. Ang, J. Appl. Phys., 2021, 129, 100902.

53 M. Rahmani, A. Moadhen, M.-A. Zaïbi, A. Lusson, H. Elhouichet and M. Oueslati, J. Alloys Compd., 2009, 485, 422-426.

54 M. Ahmad, K. Rasool, M. A. Rafiq, M. M. Hasan, C. B. Li and Z. A. K. Durrani, Phys. E, 2012, 45, 201-206. 